\title{
PROSODIC ORGANISATION OF STATIC URBAN LANDSCAPE DESCRIPTIONS IN ENGLISH PROSE
}

\author{
Inna Humeniuk \\ Sumy Makarenko State Pedagogical University, Sumy, Ukraine \\ ingum1976@gmail.com
}

\begin{abstract}
In the article on the basis of a systemic analysis of English landscape descriptions' functional, semantic and structural characteristics the author gives the most common definition of a landscape description, outlines the eight-level classification of their linguistic features, in which the main level of descriptions' identification is their belonging to the locality type. In the paper, the author performs a detailed analysis and modelling of language units' interaction in the landscape descriptions of oral actualisation. The model allows distinguishing the direction of prosodic, lexical and grammatical means' interaction in the organisation of the aforementioned descriptions having different degrees of their narrative dynamics and the level of emotional-and-pragmatic potential. The suggested model and the landscape descriptions' classification serve as methodological grounds for the experimental phonetic study of static urban landscape descriptions' prosodic organisation. The article also outlines the steps of the auditory analysis methodology necessary for researching the prosodic parameters of the descriptions under study. Among other parameters, the author applies the Kalyta-Taranenko $K$-criterion for the evaluation of a text fragment's level of emotional-and-pragmatic potential. The results of the auditory analysis enable the author to come up with the invariant prosodic pattern of English static urban landscape descriptions' intonation organisation. This invariant pattern makes it possible to classify them perfectly well during their oral realisation. The paper also outlines the prospective scientific studies of other kinds of descriptions in different linguistic spheres in general and in phonetics in particular.
\end{abstract}

Keywords: static urban landscape descriptions; emotional-and-pragmatic potential; auditory analysis; invariant pattern; prosodic organisation; oral actualisation.

\section{Introduction}

Description and its kinds (portrait, landscape, interior, etc.) as one of the composite textual forms, has attracted the attention of scientists of different linguistic and art branches. In spite of a relatively sufficient level of researching this problem, in linguistics English landscape descriptions' prosodic characteristics have been beyond any scientific interest. However, there is a popular belief that it is the prosodic organisation that plays a great role in identification of a fiction text or its fragments according to its type, kind and pragmatic orientation.

In view of this, we have focused our attention on studying static urban landscape descriptions of English prose. The objective of the paper is to ascertain the prosodic characteristics of English static urban landscape descriptions by means of performing their auditory analysis. Studying the intonation distinctive features of these landscape descriptions made it possible to substantiate the invariant intonation pattern, which enables their oral actualisation.

\section{Methodological stipulations to the study of English prose static urban landscape descriptions}

Methodological grounds to the study of English prose static urban landscape descriptions comprise a functional and communicative approach to researching the specificity of landscape descriptions' intonation organisation (Artjomov, 1974; Kalyta, 2001), general theoretical phonetic and phonological views on the mechanisms and laws of phonetic segmental and suprasegmental units' functioning in oral texts (Taranenko, 2017; Brazil, 1997; O'Connor, 1984), the principle of conserving the utterance emotional-and-pragmatic potential (Kalyta \& Taranenko, 2012, pp. 186-191; Kalyta 2018, p. 190), which served as a basic principle for distinguishing the emotional-and-pragmatic potential of English landscape descriptions.

\section{Defining the English prose static urban landscape descriptions' linguistic features}

The landscape description as a component of the novel compositional structure is considered both from broad and narrow views. According to the broad view, the landscape is any unlimited space of the outer world, a geographical relief in terms of physical geography (Kozhevnikov \& Nikolajev, 1987, p. 272). In accordance with the narrow view, the landscape description is a picture, created in a specific art genre (Busel, 2002, p. 200). In literature, a landscape description is considered as a verbal description of nature or as a fiction novel's compositional component (Grom'jak et al., pp. 527-529). In our study on the basis of the analysis of scientific findings concerning landscape descriptions' definitions we have formulated its most comprehensive definition: the landscape description as a compositional component of a fiction work has 
different artistic roles depending on the author's style, literature trend, genre, idea and the epoch of its creation; and it is an image system element, which functions as a background in a fiction work.

Differentiation of the classified characteristics of landscape descriptions (Humeniuk, 2009, pp. 165-169) was made according to such criteria: 1) locality type (urban, rural); 2) landscape kind (mountainous, water, plain); 3) season (summer, winter, autumn, spring); 4) part of the day (morning, afternoon, evening, night); 5) dynamic degree (static, static-and-dynamic, dynamic); 6) position in the text structure (isolated, fragmental, contaminated); 7) textual size (short, medium, long); 8) the level of emotional-and-pragmatic potential (high, medium, low). In the presented classification the main characteristic is belonging to the locality type because other differential criteria of the descriptions under study enable distinguishing hierarchically less sufficient quantitative and qualitative indicators.

The studying of static urban landscape descriptions' intonation organisation resulted in creating the model of multilevel language units' interaction in the oral actualisation of landscape descriptions (Humeniuk, 2011, pp. 161-165). The model reflects a step-by-step mechanism of the integral influence of these means on intonation organisation peculiarities and creation of a certain emotional-and-pragmatic potential in different landscape descriptions. The main structural characteristics of the landscape description text are reflected on the upper level of the model. The lexical level plane consists of lexemes, which belong to different lexical-thematic groups. The two main ones comprise subjective and sensory lexicon and subordinated to them lexical-and-semantic fields (toponyms, hydronyms, faunonyms, phytonyms, motion words, graminal lexemes; colour words, odorysms, sound words, sensory lexemes).

On the third plane of the model, the grammatical structure of landscape descriptions is presented. It can be represented by such parts of speech: locative nouns, static and motion verbs, relative and qualitative adjectives, locative adverbs and prepositions. Different language level units, interacting with segmental (phonemes, their clusters and phonesthemes) and suprasegmental (pitch, range, loudness, tempo, voice quality, utterance stress, pausation, rhythm) phonetic units lead to a corresponding intonation organisation of landscape descriptions. The substantiated interpretation of a graphic model of all language level means' interaction in landscape descriptions' actualisation can form a theoretical and terminological basis for distinguishing monovector and multivector interactions of intonation and lexical-and-grammatical means, which take part in organising the aforementioned descriptions with different dynamic degrees and levels of emotional-and-pragmatic potential. As a result of the multilevel language means' interaction analysis, we can state that on condition of their monovector interaction the role of intonation is subsidiary. The reason for this is the expression of landscape descriptions' meaning is made due to the integration of multilevel language units' potential without a significant superiority of a definite language system. A multivector direction of lexical, grammatical, phonetic means' interaction presupposes an unequal distribution of the mentioned above potential in realisation of English landscape descriptions. Phonetic means can change the modality and meaning of landscape descriptions giving them in such a way an opposite emotional colouring. Besides, a multivector interaction of language units of all levels (lexical, grammatical, phonetic) influences the landscape descriptions' intonation organisation and functions compensatorily.

The developed classification of landscape descriptions' linguistic characteristics and an interpretation model of multilevel language units' interaction in English landscape descriptions' organisation serve as a reliable methodological tool for working out the programme and methodology of the experimental phonetic study. It is aimed at researching the intonation means' organisation of static urban landscape descriptions and performing the adequate interpretation of its results.

\section{Defining the algorithmic pattern of studying the intonation organisation of English prose static urban landscape descriptions}

To fulfil the practical part of the study we developed a complex programme and methodology of the research according to which the experimental defining of common and differential features of invariant and variant intonation patterns were made to state the intonation means' interaction regularities in English static urban landscape descriptions' realisation. The experimental study programme included the following steps: the choice of language material and its presenters, the landscape descriptions' auditory analysis by phoneticians, the summary of the experimental results and their linguistic interpretation. The suggested methodology guaranteed a succession of experimental material corps formation and sequence of auditory analysis. Observance of all the experimental phonetic study programme and methodology stages made it possible to fulfil static descriptions' auditory analysis and make an adequate interpretation of the obtained results. 


\section{Results of the auditory analysis of static urban descriptions' prosodic organisation}

The data on the frequency of the intonation group head pitch prove that static urban landscape descriptions are characterised by a high recurrence of the mid-raised and high heads with the dominance of the first type. It manifests the intonation groups containing a new idea as well as they can serve as informative or emotional centres of descriptions. A distinctive feature of urban descriptions is the prevalence of syntagms with the level head and a lower rate of other kinds of heads. The level head, basically, is registered in the most common descending stepping scale, being a distinctive feature of a monologue.

The data on scale type's frequency in static landscape descriptions show a high recurrence of gradually descending stepping and gradually descending stepping broken scales, which intensify the semantic value of an intonation group in the description. If they are accompanied by loudness and temporal modifications, complex rhythm, broadening of pitch range (broadened $\rightarrow$ broad), tonal interval modifications in some sectors of an intonation contour, they give a landscape description the mid or high level of the emotionaland-pragmatic potential. The functioning of gradually descending scandent and gradually ascending stepping scales is qualified as not frequent. However, these scales facilitate conveying different modal meanings of the text, such as: speaker's negative attitude to the described details, admiration, surprise, heroes' negative emotions and feelings. Moreover, they highlight the main idea or climax of a description, emphasise the semantic value of some fragments or contrast the ideas, thus raising the landscape description's level of the emotional-and-pragmatic potential.

The auditory analysis results prove that static landscape descriptions stand out due to the dominance of falling, rising and level tones and their variants, as is shown in the given fragment, e.g.:

And, then, $\xi$ as she 'walked a'long the, street, $\xi$ a pro'digious , hammering and , clanging $\xi$ 'came to her 'ears $\mid$ and 'peering, down $\xi$ a'long 'dim 、alley, $\xi$ she re'membered that 'Missis $\uparrow$ Cardew . Trench $\xi{ }^{-}$had

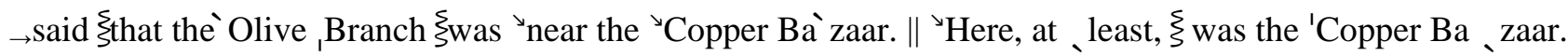
$\|$ Vic'toria 'plunged 、in, | and for the 'next $\uparrow$ three- , quarters of an, hour $\xi$ she for'got the .Olive,Branch $\xi$ - com , pletely. || The 'Copper Ba zaar $\xi$ fascinated her. || The' blow-lamps, $\xi$ the 'melting , metal, $\xi$ the 'whole

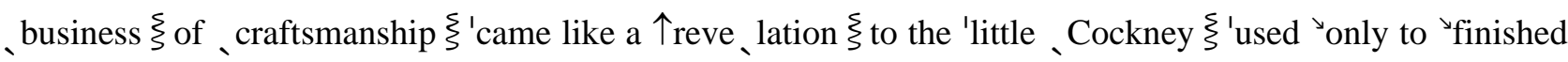
, products $\xi$ stacked up for 、 sale. $\|$ She 'passed 'out of the $\uparrow$ Copper Ba, zaar $\xi$ 'came to the $\uparrow$ gay $\cdot$ striped , horse, blankets, $\xi$ and the 'cotton 'quilted bedcovers. $\|$. Here $\xi$ Euro'pean, merchandise $\xi$ 'took on a $\uparrow$ totally different 、guise, $\mid$ in the 'arched $\cdot c o o l$, darkness $\xi$ it had the e'xotic 、quality $\xi$ of 'something 'come from $\uparrow$ over seas, $\xi$ 'something 、strange $\xi^{-}$and, rare.|| 'Bales of $\uparrow$ cheap •printed, cottons $\xi$ in 'gay, colours $\xi$ 'made à feast for the , eyes $\|$ (Christie, 2004).

The aforementioned example is characterised by the use of high and low variants of falling and rising terminal tones. A low-rising tone actualises the initial intonation group of the analysed description (e.g.: And ,then, $\xi \ldots$, etc.) and indicates the incomplete idea and its further developing. In other cases a medial intonation group with a low-rising tone in the description (e.g.: as she, walked a'long the, street $\xi$; and for the 'next $\uparrow$ three- quarters of an, hour $\xi ;$ ' 'passed 'out of the $\uparrow$ Copper $B a, z a a r \xi$, etc.) is typical of conveying the details or proceeding of the events in a description. The syntagms, defining the information mentioned above, are pronounced with a low-rising tone, e.g.: 'Bales of $\uparrow$ cheap printed, cottons $\xi$ in 'gay, colours $\xi . .$. , etc. Only the initial tone group (e.g.: Thé blow-lamps $\xi$, etc.) is pronounced with a high-rising tone because this syntagm introduces the enumeration of described details, which fascinated the main character. Realisation of the majority of syntagms with a low-falling tone is a very feature of a monologue. Low-falling and level tones add persuasiveness to the description of the oriental city bazaar and make it possible to define it as a static one. Admiration and surprise at the Copper Bazaar diversity and things never seen before are emphasised by the intensification of semantic centres with the special rise (e.g.: ... a $\uparrow$ reve lation; $\uparrow$ Copper $B a$,zaar; $\uparrow$ totally . different; from $\uparrow$ over seas; $\uparrow$ cheap •printed, cottons... etc.), and also pronouncing rhythimic groups with a high-falling terminal tone (e.g.: ...'came to her'ears,| that the`Olive ,Branchई was "near the 'Copper Ba`zaar.\| etc.). A compound intonation contour in the final syntagm (e.g.: ...'made a 'feast for the eyes.\|) draws a listener's attention to Victoria's supernatural and new impressions of what she has seen. A high pitched terminal tone also emphasises the intonation group generalising the picturesque view of Baghdad. The description's level of emotional-and-pragmatic potential is high owing to the outlined intonation organisation. 
At the general tendency of the pitch range actualisation due to the emotional degree and static-anddynamic dominance of urban descriptions we registered the dominance of the mid and narrowed pitch range variants and much smaller data on the broadened and broad pitch range in the intonation structure of static urban descriptions. This is a characteristic feature of static descriptions.

The analysis of the tonal interval frequency verifies a high recurrence of the zero tonal interval in urban descriptions, which facilitates to comprehend semantic unity of utterances and text cohesion. Static landscape descriptions stand out with the full range of the intersyntagmatic tonal interval. The most recurrent ones are the positive mid, broadened and broad intervals, which occur between the adjacent tone units of the following urban description, e.g.:

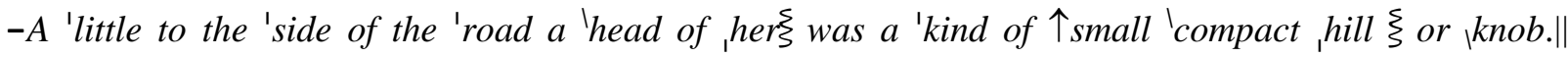
-Vic'toria 'left the track $\xi$ and 'made her 'way to the $\backslash$ knob, | the 'sides of $\cdot$ which were $\uparrow$ quite steep,, and

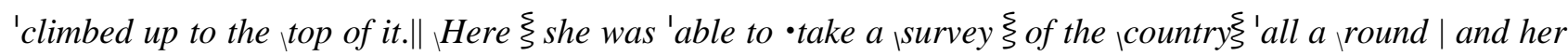

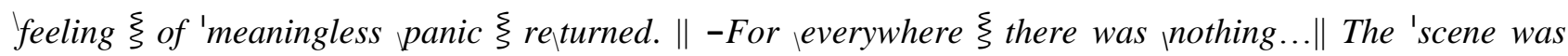

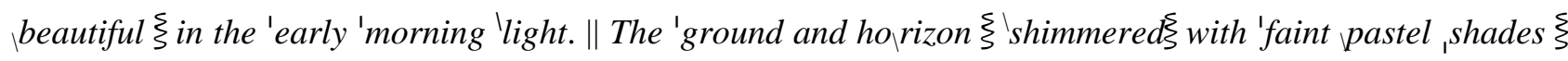
of 'apricot and 'cream and 'pink | on 'which were 'patterns of shadows. || -It was 'beautiful §but frightening.\| '. I'know what it 'means, now,', thought Vic $\rightarrow$ toria, | 'when any one, says $\xi$ they are a'lone in the ,world...' (Christie, 2004).

As it is seen, a sufficient pitch level fluctuations between the tone groups (e.g.: The 'ground and

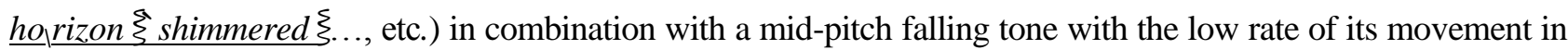
the word horizon gives the description a high level of its emotional-and-pragmatic potential. It is also facilitated by the complex intonation contour with two falling tones, differing in pitch level (e.g.: Thè scene was beautiful $\xi$, etc.). The first one emphasises the subject. The fluctuation from a low-falling tone (e.g.: The 'ground and ho $、$ rizon $\xi$,etc.) to its high variant (e.g.: ... 'shimmered $\xi$, etc.) highlights the shimmering of different colours. The descending sliding scale (e.g.: of 'apricot and 'cream and 'pink $\mid$ on "which were "patterns of shadows.\|, etc.) draws a listener's attention to colours, which describe the morning desert, raising in such a way the utterance's emotional level.

In spite of the occurrence of a full range of positive interval types between the pre-head and head, static urban descriptions are characterised by the significant functioning of mid and broadened pitch intervals. Such intervals, accompanied by the increased loudness and accelerated tempo, mark the initial and climax tone groups in descriptions. Only in these descriptions an insufficient percentage of the broad interval is registered, which is marked by the high head. They manifest the raising of narration dynamics and add semantic weight to such intonation groups. Tonal interval fluctuations (broadening or narrowing) raise the level of the emotional-and-pragmatic potential and the role of dynamic dominance (in case of broadening) or they do not distinguish a certain part of a text as a prosodically significant one (in case of narrowing).

The most frequent tonal interval is a zero one occurring between the scale and nucleus in tone groups of static urban landscape descriptions. It is typical of the tone groups marked by a level or falling tone and a low level tail. These kinds of tonal fluctuations are characteristic for the intonation groups pronounced with a falling tone. They are emotional or information centres in descriptions. In static urban landscape descriptions, we also registered positive broadened and broad intervals with the prevalence of the latter between the nucleus and the tail. In the following urban description 'Bird- ‘cit $y \mid$ was 'built bet'ween the $\uparrow$ Rio |Grand $\mid$ and a 'deep 'wide $\uparrow E$ 'o $l, \mid$ that 'used to be $\xi$ the 'old 'bed of the viver. || The 'bank between the stream | and its 'old bed | was \cracking $\xi$ and 'giving a way, |, when we ,saw it, | on a'ccount of the $\uparrow$ high water $\xi$ 'caused by the 'rain \| (O'Henry, 2001) a mid-pitched falling tone with an ascending-and-falling movement in the nuclear syllable and a low level movement in the tail is registered. Such a positive broadened tonal interval marks the tone group, describing the climax moment of the citizens' lost hope for rescue from a natural disaster (e.g.: The 'bank bet'ween the , stream $\mid$ and its 'old , bed $\mid$ was $\backslash$ cracking $\xi$, etc.). Interaction of a broadened interval between the nucleus and tail, moderate loudness and slowed down tempo convey the foreboding of the city's inevitable destruction from the flood. These prosodic peculiarities raise the fragment's emotional-and-pragmatic potential to a high level. The approximated figures of a negative broadened interval and insufficient percentage of a negative broad interval functioning in static urban descriptions also result in the increase of descriptions' level of emotional-and- pragmatic potential and its dynamic dominance. It is possible due to the combination of the mentioned above intervals with tempo and 
loudness modifications, voice quality fluctuations, prevailing perceptive and short pauses, complex intonation contours, etc.

According to the research findings, perceptive pauses are characteristic for static landscape descriptions, since they serve to ensure a semantic cohesion of tone groups in the analysed fragment e.g.:

'Down in the west $\xi$ the 'setting sun\} had 'left a $\uparrow$ streak of 'fiery red, $\xi$ which glared upon the

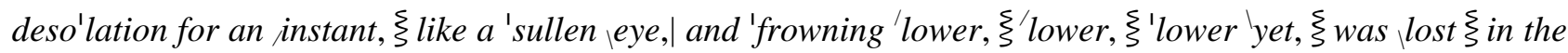
'thick \gloom of ,darkest $、$ night $\|$ (Dickens, 1994, pp. 49-50).

This kind of intersyntagmatic pausation accompanied by a narrowed pitch range and accelerated tempo

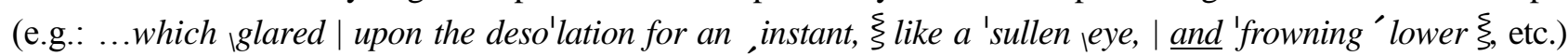
conveys a semantic contrast in the description, namely the transition from day to night. The high level of emotional-and-pragmatic potential of this description is achieved due to a medium pause duration (e.g.: ...like a 'sullen veye (..., etc.), which follows the intonation group, describing the last light moment of the day, where the sun gleam is figuratively compared with a person's gloomy, sad look.

Intersyntagmatic pauses are usually actualised after the first of the two subject group attributes or a part of the compound predicate for drawing listener's attention to the information centre of a tone group, sentence or the whole descriptive fragment. Intersyntagmatic pauses, accompanied by the special rise, intensify the semantic value of some lexemes as the most weighty ones. The presented description The 'melting 'snow

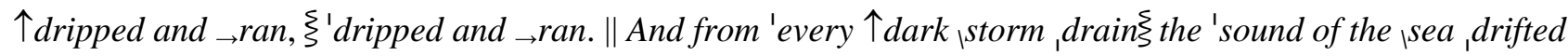
.up. \|A 'dark, ${ }^{\xi}$ 'winter, sea,, 'now 'strongly , ebbing $\|(\mathrm{King}, 2007)$ provokes sadness, agitation, ominous foreboding due to the all-level language means' interaction, in which intonation units play a significant role. In the example of intonation groups with the low pre-head prevail after the tone groups, which are

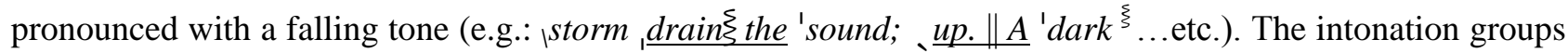
with a broadened pitch range are pronounced with high, mid, low falling and mid, low rising tones. Owing to the alteration of falling tones of different pitch levels and the lexemes accentuated with the special rise, the given description is not perceived as a monotonous one. Besides pronouncing the proclitics in the intonation groups with the intonation parallelism (e.g.: The 'melting 'snow $\uparrow$ dripped and $\rightarrow$ ran, $\xi$ 'dripped and $\rightarrow$ ran. $\|$, etc.) and in other intonation groups (e.g.: And from 'every $\uparrow$ dark ${ }_{s}$ storm, drain $\xi$, etc.) on a higher pitch level than the enlitics adds a high emotional degree to the whole description. Such a pitch movement in the melodic contour resembles a fast movement of the snow, melting and running in streams on the ground. The static nature of the urban description is maintained by falling tones in the majority of intonation groups. At the same time pronouncing the initial tone groups (e.g.: The 'melting 'snow $\uparrow$ dripped and $\rightarrow$ ran, $\}$ 'dripped and $\rightarrow$ ran.|) with mid and low level tones accompanied by the moderate loudness and accelerated tempo is associated with a perpetually falling snow which melts at once. Moreover, it emphasises the static nature of a peaceful description.

Pronouncing some tone groups with the accelerated tempo and accentuating some words with the special rise raises the level of the urban description's emotional-and-pragmatic potential. Although the final part of the fragment (e.g.: A 'dark ${ }^{\xi}$, winter, sea, \}'now 'strongly , ebbing.||) is realised with the slowed down tempo and moderate loudness, the intrasyntagmatic pause intensifies the description of the stormy sea tide. In another tone group such pauses distinguish the verb denoting downward water movement (e.g.: 'dripped ${ }^{\xi}$ and $\rightarrow$ ran), which is accompanied by the initial intonation group pronounced with a gradually descending broken stepping scale (e.g.: 'snow $\uparrow$ dripped and $\rightarrow$ ran,,$\ldots$...) that breaks a monotonous lexical repetition. Such a prosodic organisation not only proves the description's static nature but also conveys the inevitable advent of spring, awaking of nature, waiting for the warmth and sun light. The aforementioned intonation characteristics give the fragment a high level of emotional-and-pragmatic potential.

The descriptions under study are basically pronounced with moderate and/or slowed down tempo in combination with a simple regular rhythm, moderate loudness, which are among the parameters of English prose static descriptions. This is illustrated by the following descriptive fragment, e.g.:

A 'wavering yawuuh, rose in a,purple ,gloom,| and the 'young 'man frowned. $\|$ It was some Tom-cat's , love , song, | and there was 'nothing, pretty about, that (slowed down tempo).||" (Christie, 2004).

This example is realised with a slowed down tempo at the end, loudness fluctuations (from moderate to low), mid and low-falling tones (e.g.: A 'wavering yawuuh, rose in a purple , gloom $\mid . .$. ) that raise the 
description's emotional-and-pragmatic potential to the mid level. Spring evening silence in the city, cloaked with the purple mist, is interrupted by the cat's mewing. It makes the young man, enjoying the view of the coming spring, frown and prick up his ears. Pleasant emotions, caused by watching the May nature riot, are changed to anxious forebodings (e.g.: ... and there was 'nothing , pretty about, that $\|$ ), which are conveyed by the slowed down tempo and lowered loudness, marking the lexeme pretty with a low-falling tone and a narrowed pitch range of the intonation group. Such intonation peculiarities create suspense of something unusual and unpleasant, hints at the further development of the events (the girl's cruel murder).

The summary of the loudness modifications in static urban landscape descriptions verifies a high recurrence of its moderate kind. Besides, these descriptions stand out with significant data of lowered loudness. The registered loudness variants in the aforementioned descriptions in combination with other parameters' modifications (moderate/slowed down tempo, simple rhythm, falling tone, intrasyntagmatic pausation and prevalence of short and mid pauses) are the distinctive features of static urban descriptions. In case of loudness fluctuations within a descriptive fragment (raised $\rightarrow$ moderate $\rightarrow$ lowered loudness) accompanied by falling and rising tones, narrow and broadened pitch range in some textual fragments, temporal modifications (slowed down $\rightarrow$ accelerated tempo), gradually descending sliding scale in some intonation groups illustrate the static nature of the urban winter landscape. Such prosodic organisation results in the description's high level of emotional-and-pragmatic potential, e.g.:

... and his 'ears were deafened (slowed down tempo) by the'thundering of , water. $\xi_{\text {(moderate tempo) }}$ as it 'rolled and 'roared and 'raged $\xi$ among the 'dreadful caverns it had, worn, $\xi$ and 'fiercely, tried $\xi$ to under'mine the e e

The carried out auditory analysis enabled us to ascertain the invariant prosodic pattern of static urban landscape descriptions: a mid-raised head, functioning of all kinds of scales, low-falling and low-rising terminal tones, mid and widened pitch range, positive widened and negative wide intersyntagmatic pitch interval, positive mid and widened interval variants between the pre-head and head, negative mid, narrow tonal interval in the segment "scale - nucleus", perceptive and intrasyntagmatic pauses, moderate and slowed down tempo, moderate loudness.

\section{Conclusions}

The developed classification of landscape descriptions' linguistic features and a multilevel language units' interaction model in actualising the aforementioned descriptive fragments may serve as a theoretical ground for the further developing a fuller classification of not only landscape descriptions but also other kinds of this composite speech form and their realisation specificities. The data, obtained during the auditory analysis, prove that static urban landscape descriptions have a specific intonation organisation, which enables their correct identification according to their type (urban) and kind (static). We believe that the results presented in the paper may serve as a starting point for a further scientific research of prose descriptions in the field of text linguistics, stylistics, general phonetics and intonology in mono- and multisystem languages.

\section{References:}

Artjomov, V.A. (1974). Metod strukturno-funnktsional'nogo izuchenija rechevoj intonatsii [The method of structural-and-functional study of speech intonation]. Moscow, Russia: Nauka.

Brazil, D. (1997). The Communicative Value of Intonation in English. Cambridge: Cambridge University Press.

Busel, V.T. (2002). Velykij tlumachnij slovnyk suchasnoi' ukrai'ns 'koi' movy [Great explanatory dictionary of the modern Ukrainian language]. Kyiv, Irpin': Perun.

Christie, A. (2004). They Came to Baghdad [Audiobook, Running time 3 hrs 27 mins] (narrated by Lisa Rae Campbell). Kyiv, Ukraine: TOV "SidiKom".

Dickens, Ch. (1994). The Christmas Books. London: Penguin Books.

Grom'jak, R. T. Kovaliv, Ju. I. \& V. I. Teremok (Eds.) (2007). Litreraturoznavchyj slovnyk-dovidnyk [Literary referential dictionary]. Kyiv: Vydavnychyj centr "Academija".

Humeniuk, I. (2011). Eksperymental'no-fonetychne doslidzhennja anglomovnyh prozovyh opysiv pryrody [Experimental-andphonetic research of English prose landscape descriptions]. Visnyk Cherkas'kogo universitetu. Serija: Filologichni nauki, 213, 161-165.

Humeniuk, I. (2009). Systematyzatsija oznak opysiv pryrody suchasnoi' anglomovnoi' prosy [The systematisation of the features of modern English prose landscape descriptions]. Naukovi zapysky. Serija: Filologichni nauki: Movoznavstvo, 81 (2), 165-169.

Kalyta, A. (2001). Fonetychni zasoby aktualizacii'smyslu anglijs'kyh emocijnyh vyslovljuvan' [Phonetic means actualising the meaning of an English emotional utterance]. Kyiv, Ukraine: Publishing centre of Kyiv National Linguistic University.

Kalyta, A. \& Taranenko, L. (2012). Perceptivna j instrumental'na ocinki emocijno-pragmatychnogo potencialu vislovlen' [Auditory and instrumental evaluation of the utterance emotional-and-pragmatic potential]. Naukovij visnik Volins'kogo nacional'nogo universitetu imeni Lesi Ukrä̈nki. Serija: Filologichni nauki: Movoznavstvo, 24 (249), 186-191. 
Kalyta, A. (2018). The Energetic Potential of Speech Pauses. Advanced Education, 9, 185-193. https://doi.org/10.20535/24108286.135068

King, S. (2007). The Green Mile. London: Penguin Books.

King, S. (2007). Selected Stories. Retrieved June 15, 2018 from http://free-books.me/audio/hudozh/fantastica/63148-Kingrasskazymp3

Kozhevnikov, V.M. \& Nikolajev, P.A. (Eds.) (1987). Literaturnyj entsiklopedicheskij slovar' [Literary encyclopaedic dictionary]. Moscow, Russia: Sov. encyclopaedia.

O’Connor, J. D. (1984). Phonetics. London: Penguin Books Ltd.

O’Henry (2001). Ten Best Stories [Audiobook, Running time 3 hrs 38 mins] ( narrated by Joseph Samuel Bagley). Kyiv, Ukraine: TM "Krajevyd".

Taranenko, L. (2017). Correlation of the English Fairy Tale's Plot Structure and its Prosodic Organisation. Advanced Education, 7 , 114-122. https://doi.org/10.20535/2410-8286.105385

Received: August 15, 2018 Accepted: October 04, 2018 